\title{
Benznidazole-induced genotoxicity in diploid cells of Aspergillus nidulans
}

\author{
Edilson N Kaneshima, Marialba A Alves de Castro-Prado*/+
}

Universidade Estadual de Maringá, Departamento de Análises Clínicas *Departamento de Biologia Celular e Genética, Av. Colombo 5790, 87020-900 Maringá, PR, Brasil

Genotoxic effects of benznidazole were studied by the induction of homozygosis of genes previously present in heterozygous. UT448//A757 diploid strain was used in the benznidazole's recombinagenesis test. Although toxic effects on growth of colonies were not observed, 75 and $100 \mu \mathrm{M}$ benznidazole induced an increasing of mitotic recombination events in diploid strain. Results were related to the induction of chromosomal breaks by the antiparasitic drug.

Key words: benznidazole - somatic recombination - genotoxicity - homozigotization index

Chagas disease, caused by Trypanosoma cruzi, is one of the most serious parasitic diseases of Latin America, where some 16 - 18 million people are infected by the $T$. cruzi (WHO 1991). Although in Brazil the disease is under strict control, there are still about 4 million people infected by the parasite (Dias 1998). Benznidazole is used in the treatment of Chagas disease in the acute phase, at the start of the chronic phase, in congenital cases and accidental infection (Fragata Filho et al. 1997). Several adverse effects have been described in patients undergoing treatment with the anti-parasitic drug (Cançado 1997, Fragata Filho et al. 1997).

The mutagenic action of the benznidazol has been studied in streptomycin-resistant Klebsiella pneumoniae strain and in Salmonella typhimurium TA100 strain. Mutagenic effect of the drug has also been observed in TA100 strain in the presence and in the absence of the microsomal hepatic fraction of mice, using 50 to $1000 \mu \mathrm{M}$ concentrations (Voogd et al. 1975, Nagel \& Nepomnaschy 1983).

The mutagenic activity of benznidazole has also been determined in the simplified version of Ames test with sensitive (TA100 and TA102) and less sensitive (TA98 and TA97) S. typhimurium strains (Melo \& Ferreira 1990) in the same plate. The drug's mutagenic effect was accounted to the interaction of reactive metabolites of benznidazole with the DNA and with nuclear proteins (Gorla et al. 1986, Zahoor et al. 1987, Ferreira et al. 1988).

Benznidazole's genotoxicity has been studied in peritoneal macrophages of mice treated with benznidazole (Lacava \& Luna 1994). These authors reported the clastogenic effect of the drug owing to increase in the frequency of chromatid breaks and to the formation of acrocentric chromosomes.

Moya and Trombotto (1988) demonstrated the benznidazole's clastogenic effect in patients treated with the drug. High micronucleus percentage and increase in the

+Corresponding author. E-mail: maacprado@uem.br Received 18 December 2004

Accepted 15 April 2005 frequency of fragile sites (gaps or breaks in the metaphase chromosomes) were observed in cytogenetic analysis.

Bocchi et al. (1998) detected a high incidence of malignant neoplasms in patient with Chagas disease who had undergone heart transplant and treated with benznidazole. On the other hand, although Teixeira et al. (1994) observed a high incidence of lymphoblastic lymphoma in mice treated with benznidazole, Andrade et al. (2003) verified that the administration of the benznidazole in immunosuppressed mice and chronically infected by $T$. cruzi did not result in the emergence of lymphomas or other neoplasms.

In spite of these contradictory results, the clastogenic effect of benznidazole (Lacava \& Luna 1994) suggest its participation in the carcinogenic process due to the occurrence of mitotic crossing-over that induces the loss of heterozygosity of tumor suppressor genes (Zimmermann 1971, Weinberg 1991, Beumer et al. 1998). The evaluation of the recombinagenic potential of benznidazol in heterozygous cells of Aspergillus nidulans will be provided. Information on the participation of the anti-parasitic drug in the carcinogenesis process will be thus ensued.

\section{MATERIALSAND METHODS}

Strains and culture media - A. nidulans strains used are described in Table I. Minimum medium (MM) was Czape-Dox with 1\% (w/v) glucose. Complete medium (CM) has previously been described by Pontecorvo et al. (1953) and Van De Vate and Jansen (1978). Supplemented medium (SM) consisted of MM plus nutriments required by each strain. Solid medium contained $1.5 \%$ agar. Incubation occurred at $37^{\circ} \mathrm{C}$.

Methods - General methodology followed previous reports (Roper 1952, Pontecorvo et al. 1953). Heterokaryons were prepared in liquid MM plus 2\% CM. Cleistothecia were obtained from heterokaryons after 21 days of incubation in sealed petri dishes containing MM, supplemented according to the requirements of the crossed strains. Diploids were prepared by method described by Roper (1952).

Evaluation of drug toxicity - Filter-sterilized aqueous solutions of benznidazole (Roche), $99.8 \%$ pure, was added 
TABLE I

Genotype of Aspergillus nidulans strains

\begin{tabular}{|c|c|c|}
\hline Strain & Genotype & Origin \\
\hline A507 & FpaB37 (I), SulAI (I), anAl (I) pabaAl (I) & FGSC \\
\hline A837 & uvsH77 (IV), pyroA4 (IV), choAl (VII), chaAl(VIII) & FGSC \\
\hline A757 & yA2 (I),methA17 (II), pyroA4 (IV) & FGSC \\
\hline B211 & $\begin{array}{l}\text { yA2 (I), bioAl (I), AcrAl (II), wAl (II) methAl7 (II), (IV), } \\
\text { pyroA4, uvsH (IV), choAl (VII), chaAl(VIII) }\end{array}$ & Busso et al. 2001 \\
\hline B1 & $y A 2(I), \operatorname{pabaA1} 24(I), \operatorname{biAl}(I)$ & LGM \\
\hline UT184 & $\begin{array}{l}\text { SulA1(I),AcrA1(II), galA1 (III), pyroA4 (IV), facA303 lacAl(VI) } \\
\text { (V), lacA1 (VI), sB3 (VI), nicB8 (VII), riboB2 (VIII), chaA1 (VIII) }\end{array}$ & Utrecht, Holland \\
\hline UT448 & $\operatorname{riboA1}(I), \operatorname{pabaA1} 24(I), \operatorname{biAl}(I), \operatorname{AcrA1}(I I), w A 2(I I)$ & Zucchi 1990 \\
\hline
\end{tabular}

an, ribo, paba, bio, meth, pyro, nic, cho requirements for aneurine, riboflavin, $\rho$-aminobenzoic acid, biotin, methionine, pyridoxinine, nicotinamide, and choline, respectively; $y$ (yellow); $w$ (white), and cha (chartreuse) are conidial color markers; Acr, Sul, and Fpa, resistance to acriflavine, sulphanilamide and $\rho$-fluorofenilalanine, respectively; fac, lac, and gal, unable to grow on ammonium acetate, lactose, and galactose as the sole carbon source; sB3, sulfate transport impairment; $u v s$, sensitivity to UV radiation; gene symbols are used according to Clutterbuck (1994); FGSC, Fungal Genetic Stock Center; LGM, Laboratory of Genetics of Microorganisms of State University of Maringá.

to molten CM so that final 50,75 , and $100 \mu \mathrm{M}$ concentrations could be obtained. Conidia of diploid strains UT448/ A757 and B211//A837 were inoculated in plates containing CM (control) and CM + benznidazole (treatment). Five plates, were used for each dose and for control. Diameters of colonies were measured after 24, 48, 72, 96, and $120 \mathrm{~h}$ of incubation. Comparison of values of colony diameters with and without the drug was undertaken by Student's $t$ test.

Evaluation of the drug' recombinagenic potential Conidia of diploid strain UT448//A757 were inoculated in plates with $\mathrm{MM}+$ benznidazole $(50,75$, and $100 \mu \mathrm{M})$. Plates were incubated for 6 days at $37^{\circ} \mathrm{C}$. Treatment produced visible diploid sectors, D1-D6, identified by differentiated morphology of the original diploid. Sectors were homozygous (+/+) or heterozygous (+/- or -/+) diploid segregants, but never recessive homozygous $(-/-)$, since they did not grow in MM. Diploid sectors were haploidized spontaneously in CM after purified in MM.

After haploidization the haploid mitotic segregants from diploids D1 to D6 were purified in CM. Only mitotic stable segregants were selected for the recombinagenic test and determination of the homozigotization index (HI) (Pires \& Zucchi 1994, Franzoni et al. 1997).

Determination of the homozigotization index (HI) Conidia of each haploid segregant were transferred, oneby-one, to 25 positions in CM plates (master plates). After incubation for $48 \mathrm{~h}$ at $37^{\circ} \mathrm{C}$, colonies were transferred to the proper selective media for phenotypic analysis of haploid segregants. Nutritional markers of the haploid segregants segregate in the proportion (a) 4+:4-, if drug fails to induce recombinagenesis or (b) 4+: 2-, if drug induces crossing-over (Fig. 1). The homozygotization index $(\mathrm{HI})$, or the ratio between prototrophic and auxotrophic segregants, equal to or over $2.0(4+/ 2-)$, reveals the recombinagenic effect of the compound under analysis (Pires \& Zucchi 1994, Chiuchetta \& Castro-Prado 2002, Busso \& Castro-Prado 2004).

\section{RESULTS AND DISCUSSION}

Three different benznidazole concentrations were assayed for their ability to induce cytotoxic effects and somatic segregation in the $A$. nidulans mould. Benznidazole had no effect on colonies' morphologies and micelial growth of diploid UT448//A757 and B211//A837 strains at the three tested concentrations (results not shown).

Induction of aneuploidy and mitotic crossing-over was studied in heterozygous diploid B211//A837 strain exposed to benznidazole. Treatment of B211//A837 with benznidazole $100 \mathrm{mM}$ in CM allowed the isolation of a mitotic segregant named R1. Phenotypic analyses of R1 showed it was recombinant for Acr-w interval of chromosome II (Fig. 2). Segregant was grown in CM + benomyl (2 $\mu \mathrm{g} / \mathrm{ml}$ ) so that its mitotic stability could be analyzed. R1 did not produce new mitotic sectors with the haploidization agent and was classified as haploid segregant (results not shown). In fact, when submitted to the sexual cycle, R1 produced normal frequencies of meiotic recombination for markers of chromosomes I, IV, and VIII (Table II).

Prototrophic diploid segregants were isolated from UT448//A757 colonies, after treatment with 50, 75, and $100 \mu \mathrm{M}$ of benznidazole in MM. Diploids (D1 to D9) were submitted to spontaneous haploidization in CM (Fig. 3a,b) and the selected mitotic segregants were tested for their mitotic stability in CM + benomyl (Fig. 3c,d). Only segregants that failed to produce new mitotic sectors, demonstrating genetic stability, were selected for HI determination.

Although HI values obtained from benznidazole 50 $\mu \mathrm{M}$ were lower than 2.0 (results not shown), results obtained with 75 and $100 \mu \mathrm{M}$ demonstrate that benznidazole is effective in inducing mitotic crossing-over in A. nidulans diploid strain. HI values obtained from benznidazole 75 and $100 \mu \mathrm{M}$ (D2, D4, D5, and D6) were higher than 2.0 and statistically different from control (Table III).

The recombinagenic effect of benznidazole may be related to the induction of chromosomal breaks, such as has been observed in cytogenetic analyses of human lym- 
phocytes and of mice's peritoneal macrophages (Moya \& Trombotto 1988, Lacava \& Luna 1994).

Multiple genetic alterations, such as point mutations, chromosomal translocations and loss of heterozygosity $(\mathrm{LOH})$, are involved in the cellular carcinogenesis (Barrett 1993, Ramel et al. 1996). In human retinoblastoma, LOH is the most common mechanism by which the normal wildtype allele at the RB1 locus is lost in a heterozygous retinal cell for a null mutation. Possible chromosomal mechanism triggering LOH would include: mitotic non-disjunction with loss of chromosome bearing the wild-allele or mitotic recombination between the RB1 locus and the centromere, resulting in homozygosity of defective allele (Cavenee et al. 1991, Hagstrom \& Dryja 1999).

Somatic recombination consists of exchange events between homologous chromosomes that, following chromosome segregation and cell division, may result in homozygosis of distal genes to the point of exchange (Lasko et al. 1991, Zimmermann 1992, Beumer et al. 1998). Although the rate of spontaneous mitotic recombination in dividing cells of mammals is very low (Morley et al. 1990), it is known that mitotic recombination may occur during the repair of chromosomal double-strand and single-strand break (Galli \& Schiestl 1998, Hagstrom \& Dryja 1999, Helleday 2003, Stark \& Jasin 2003).

Benznidazole in vitro increased the frequency of the sister chromatid exchanges in human cells of hepatoma and in lymphocytes of patients treated with the drug. Drug is further capable of increasing the micronuclei frequency in the hepatoma cells (Santos et al. 1994). The clastogenic effect of the anti-parasitic agent was also observed in peripheral lymphocytes of chagasic children (Gorla 1988).

Although the mutagenic effect of benznidazole at 50 $\mu \mathrm{M}$ has been observed in S. typhimurium assays (Nagel \& Nepomnaschy 1983), this dose does not show recombinagenic effect in A. nidulans (results not shown).

Our results demonstrate that benznidazole recombinagenic effect is dose-dependent. Since somatic recombination may trigger neoplasms, current analysis suggests that the carcinogenic potential of the anti-parasitic drug may be conducted by loss of heterozygosity mediated by mitotic crossing-over.

\section{No crossing-over}

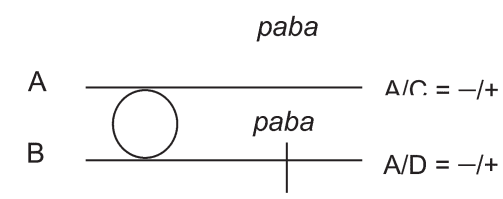

a: not grown in MM

\section{Crossing-over}

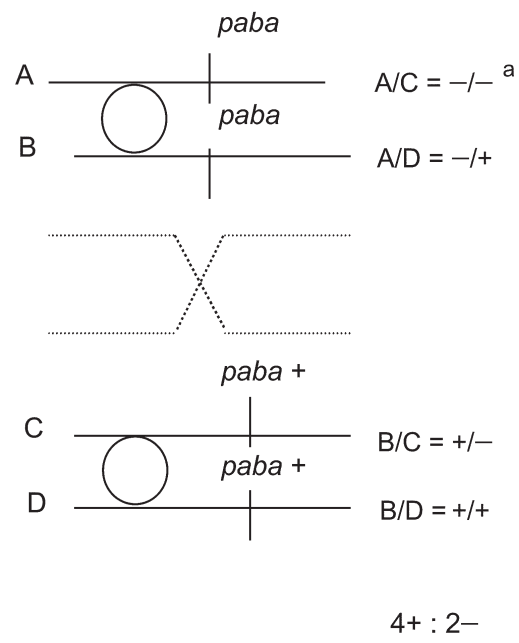

Fig. 1: origin of recombinant diploid segregants through mitotic crossing-over.

Chromosomes

$\begin{array}{lllll}\text { Strains } & \text { I } & \text { II } & \text { IV }\end{array}$

B211
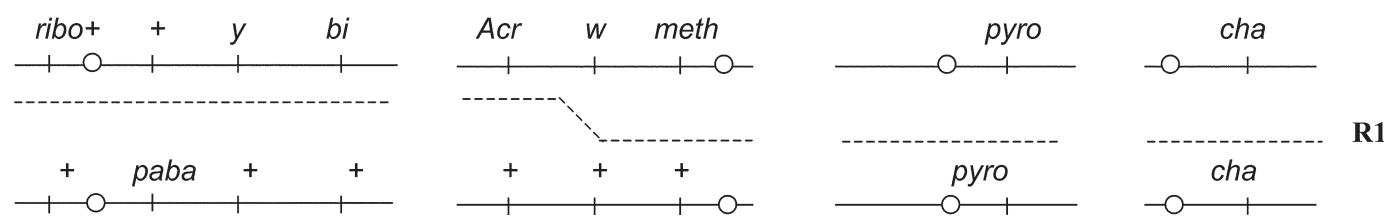

Fig. 2: schematic representation of chromosomes I, II, IV, and VIII of R1 mitotic segregant. 
TABLE II

Frequencies of meiotic recombination between markers from I, IV, and VIII chromosomes obtained in R1 x A507 cross

\begin{tabular}{lcr}
\hline & \multicolumn{2}{c}{ Frequencies of recombination (\%) } \\
\cline { 2 - 3 } Genetic interval & Control crosses & R1 x A507 \\
\hline paba-y & $15.9(21 / 132)^{a}$ & $14.0(28 / 200)$ \\
paba-bi & $21.2(28 / 132)^{a}$ & $17.5(35 / 200)$ \\
paba-pyro & $58.3(77 / 132)^{a}$ & $40.0(80 / 200)$ \\
paba-cha & $48.7(37 / 76)^{b}$ & $40.0(80 / 200)$ \\
bi-y & $5.3(7 / 132)^{a}$ & $5.5(11 / 200)$ \\
bi-pyro & $43.9(58 / 132)^{a}$ & $35.5(71 / 200)$ \\
bi-cha & $43.4(33 / 76)^{b}$ & $38.5(77 / 200)$ \\
y-pyro & $53.0(70 / 132)^{a}$ & $34.0(68 / 200)$ \\
y-cha & $46.1(35 / 76)^{b}$ & $42.0(84 / 200)$ \\
pyro-cha & $42.1(32 / 76)^{b}$ & $39.0(78 / 200)$ \\
\hline
\end{tabular}

$a$ : UT448 x A757 cross; $b$ : B1 x UT184 cross

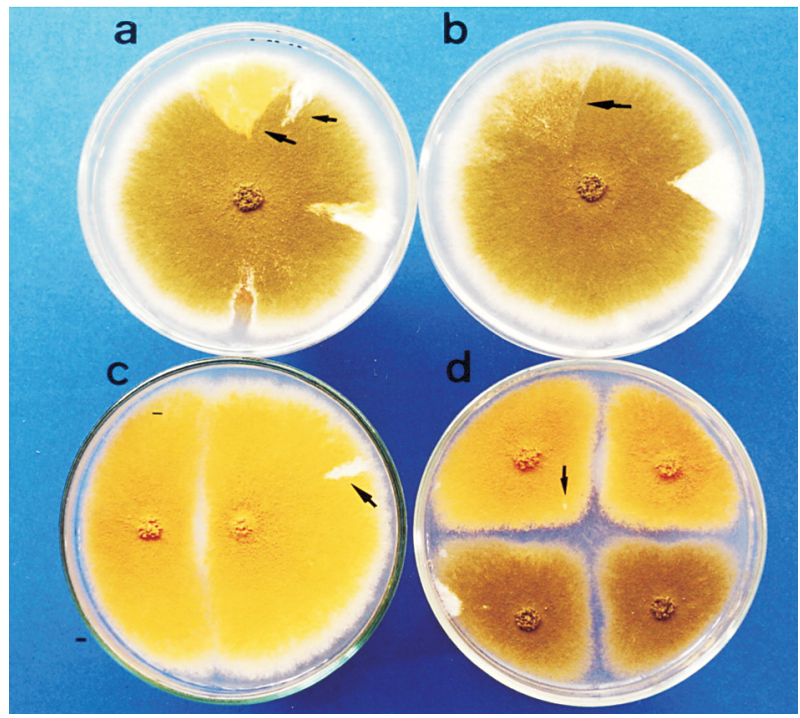

Fig. 3a, b: spontaneous haploidization of D4 diploid strain in complete medium (CM). Arrows indicate the origin of mitotic segregants; c, d: growth of mitotic segregants derived from D4 strain in $\mathrm{CM}+$ benomyl. Arrows indicate the origin of new mitotic sectors.

\section{ACKNOWLEDGMENTS}

To Dr Francisco Gualter for supplying benznidazole (Roche) and to Luzia AS Regasse for technical assistance.

\section{REFERENCES}

Andrade SG, Mesquita IMO, Jambeiro JF, Santos IFM, Portella RS 2003. Treatment with benznidazole in association with immunosuppressive drugs in mice chronically infected with Trypanosoma cruzi: investigation into the possible development of neoplasias. Rev Soc Bras Med Trop 31: 373-383.

Barrett JC 1993. Mechanism of multistep carcinogenesis ans carcinogen risk assessment. Environ Health Perspect 100: 9-20.

Beumer KJ, Pimpinelli S, Golic KG 1998. Induced chromosomal exchange directs the segregation of recombinant chromatids in mitosis of Drosophila. Genet 150: 173-188.

Bocchi EA, Higuchi ML, Vieira ML, Stolf N, Bellotti G, Fiorelli

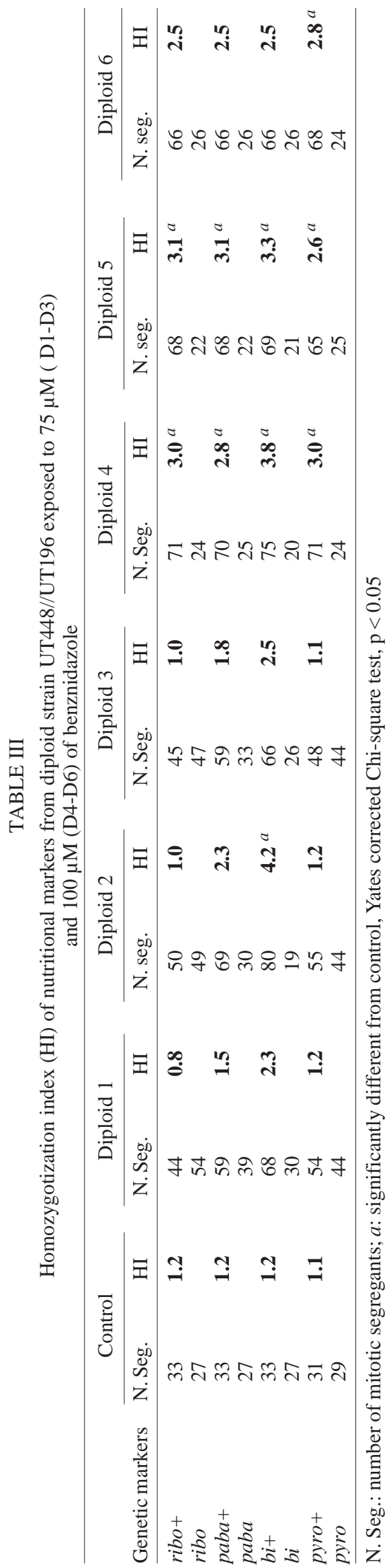


A, Jatene A, Pileggi F 1998. Higher incidence of malignant neoplasms after heart transplantation of treatment of chronic Chagas' heart disease. J Heart Lung Transplant 17: 399405.

Busso C, Castro-Prado MAA 2004. Cremophor EL stimulates mitotic recombination in uvsH//uvsH diploid strain of $A s$ pergillus nidulans. Ann Braz Acad Sci 76: 49-55.

Busso C, Chiuchetta SJR, Baptista F, Castro-Prado MAA 2001. $u v s H / / u v s H$ diploid strain allowing an efficient method to evaluate the recombinagenic effect of chemical and physical agents in Aspergillus nidulans. Act Scientiarum 23: 603607.

Cançado JR 1997. Terapêutica específica. In JCP Dias, JR Coura (eds), Clínica e Terapêutica da Doença de Chagas: Uma Abordagem Prática para o Clínico Geral, Fiocruz, Rio de Janeiro, p. 323-351.

Cavenee WK, Scrable HJ, James CD 1991. Molecular genetics of human cancer predisposition and progression. Mutat Res 247: 199-202.

Chiuchetta SJR, Castro-Prado MAA 2002. Vincristine induces somatic segregation, via mitotic crossing-over, in diploid cells of Aspergillus nidulans. Biol Res 35: 31-38.

Chutterbuck AJ 1994. Linkage map and locus list. In SD Martinelli, JR Kinghorn (eds), Aspergillus: 50 years on, Elsevier, Amsterdam, p. 791-824.

Dias JC 1998. Community participation and control of endemic diseases in Brazil: problems and possibilities. Cad Saúde Pública 14 (Supl. 2): 19-37.

Ferreira RCC, Schwarz U, Ferreira LCS 1988. Activation of anti-Trypanosoma cruzi drugs to genotoxic metabolites promoted by mammalian microsomal enzymes. Mutat Res 204: 577-583.

Fragata Filho AA, Luquetti AO, Prata A, Rassi A, Gontijo ED, Ferreira HO, Cançado JR, Coura JR, Andrade SG, Macedo V, Amato Neto V, Oliveira Jr. W, Brener Z 1997. Etiological treatment for Chagas disease. Parasitol Today 13: 127-128.

Franzoni MGM, Castro-Prado MAA, Gebara JS 1997. On the recombinagenic activity of norfloxacin in a diploid strain of Aspergillus nidulans. Cytologia 62: 39-45.

Galli A, Schiestl RH 1998. Effects of DNA-double-strand and single-strand breaks on intrachromosomal recombination events in cell-cycle-arrested yeast cells. Genet 149: 12351250 .

Gorla N, Diaz Gomez MI, Castro JA 1986. Interaction of benznidazole reactive metabolites with rat liver deoxyribonucleic acid and nuclear proteins. Arch Int Pharmacodyn Ther 280: 22-31.

Gorla N, Ledesma OS, Barbieri GP, Larripa IB 1988. Assessment of cytogenetic damage in chagasic children treated with benznidazole. Mutat Res 206: 217-220.

Hagstrom SA, Dryja TP 1999. Mitotic recombination map of 13 cen-13q14 deried from in investigation of loss of heterozygosity in retinoblastomas. Proc Natl Acad Sci USA 96: 2952-2957.

Helleday T 2003. Pathways for mitotic homologous recombination in mammalian cells. Mutat Res 532: 103-115.

Lacava ZG, Luna H 1994. The anticlastogenic effect of tocopherol in peritoneal macrophages of benznidazole-treated and ovariectomized mice. Mutat Res 305: 145-150.
Lasko D, Cavenee W, Nordenskjold M 1991. Loss of constitutional heterozyogosity in human cancer. Annu Rev Genet 25: $281-314$.

Melo ME, Ferreira LC 1990. Screening the mutagenic activities of commonly used antiparasite drugs by the Simultes, a simplified Salmonella/microsome plate incorporation assay. Rev Inst Med Trop São Paulo 32: 269-274.

Morley AA, Grist SA, Turner DR, Kutlaca A, Bennett G 1990. Molecular nature of in vivo mutations in human cells at the autosomal HLA-A locus. Cancer Res 50: 4584-4587.

Moya PR, Trombotto GT 1988. Enfermedade de chagas: Efecto clastogenico de nifurtimox y benznidazol en niños. Medicina 48: 487-491.

Nagel R, Nepomnaschy I 1983. Mutagenicity of 2 anti-chagasic drugs and their metabolic deactivation. Mutat Res 117: 237 242 .

Pires LTA, Zucchi TMAD 1994. A new method to detect potential genotoxic agensts using mitotic crossing over in diploid strains of Aspergillus nidulans. Braz J Genet 17: 371376.

Pontecorvo G, Roper JA, Hemmons LM, McDonald KD, Bufton A 1953. The genetics of Aspergillus nidulans. Adv Genet 5: 141-238.

Ramel C, Cederberg H, Magnusson J, Vogel E, Natarajan, At, Mullender, LH, Nivard JM, Parry JM, Leyson A, Comendador MA, Sierra LM, Ferreiro JÁ, Consuegra S 1996. Somatic recombination, gene amplification and cancer. Mutat Res 353: 85-107.

Roper JA 1952. Production of heterozygous in filamentous fungi. Experientia 8: 14-15.

Santos SJ, Takahashi, CS, Natarajan, AT 1994. Cytogenetic effects of the antichagasic benznidazole on human cells in vitro. Mutat Res 320: 305-314.

Stark JM, Jasin M 2003. Extensive loss of heterozygosity is suppressed during homologous repair of chromosomal breaks. Mol Cell Biology 23: 733-743.

Teixeira AR, Calixto MA, Teixeira ML 1994. Chagas' disease: carcinogenic activity of the antitrypanosomal nitroarenes in mice. Mutat Res 305: 189-196.

Van de Vate C, Jansen GJO 1978. Meiotic recombination in a duplication strian of Aspergillus nidulans. Gen Res 31: 29-52

Voogd CE, Van der Stel, JJ, Jacobs JJJAA 1975. The mutagenic action of nitroimidazoles II. Effects of 2-nitroimidazoles. Mutat Res 31: 149-152.

Weinberg RA 1991. Tumor suppressor genes. Science 254: 1138-1146.

WHO 1991. Control of Chagas disease. WHO Technical Report, Series No. 811, Geneva.

Zahoor A, Lafleur MV, Knight RC, Loman H, Edwards DI 1987. DNA damage induced by reduced nitroimidazole drugs. Biochem Pharmacol 36: 3299-3304.

Zimmermann FK 1971. Genetics aspects of carcinogenesis. Biochem Pharmacol 20: 985-995

Zimmermann FK 1992. Test for recombinagens ins fungi. Mutat Res 284: 147-158.

Zucchi TMAD 1990. Isolation of a putative recombination mutant of Aspergillus nidulans. Braz J Genetic 13: 409429. 
